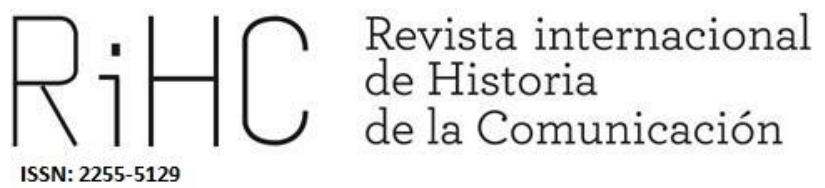

\title{
DIBUJANDO LA REVOLUCIÓN RUSA. UNA HISTORIA REVOLUCIONARIA A TRAVÉS DE LAS VIÑETAS DE LA PRENSA MADRILEÑA ${ }^{1}$
}

Drawing the Russian Revolution: A Revolutionary Story through the Cartoons of the Madrid Press

DOI: https://dx.doi.org/10.12795/RiHC.2020.i14.11

Recibido: $30 / 03 / 2020$

Aceptado: $14 / 05 / 2020$

Publicado: $15 / 06 / 2020$

María Sánchez Mellado

ORCID (D) 0000-0003-2377-0481

Universidad Pablo de Olavide, España

maria.sanchez.mellado2@gmail.com

\footnotetext{
1 Aprovecho la ocasión para agradecer los inestimables consejos del doctor Francisco Javier Fernández Roca y de la doctora Cristina Rosillo López en la realización de la investigación. Los errores, si los hubiera, son solo de mi entera responsabilidad.
} 
Resumen: Con el objetivo de comprender qué imagen de la Revolución rusa ofrecieron los periódicos de Madrid, el artículo estudia las viñetas que los diarios madrileños publicaron sobre Rusia a lo largo de 1917. Para ello se ha realizado un análisis de contenido de 84 viñetas publicadas desde el estallido de la primera revolución (febrero en Rusia, marzo en España) hasta finales de año en nueve periódicos, tanto liberales como conservadores, descubriendo que los ilustradores conectaron la Revolución rusa con la realidad española y destacaron, entre todos los acontecimientos revolucionarios, la abdicación del zar Nicolás Il y la participación de Rusia en la Primera Guerra Mundial. Palabras clave: Revolución rusa, viñetas, periódicos, Madrid.

\begin{abstract}
With the aim of understanding what image of the Russian revolution published the newspapers of Madrid, this article studies the cartoons of the Madrid press about Russia printed throughout 1917. For this purpose, a content analysis of 84 cartoons published since the outbreak of the first revolution (February in Russia, March in Spain) until the end of the year in nine newspapers, liberals and conservatives, has been carried out, finding that the Spanish cartoonists linked Russian revolution with Spanish reality and emphasized, among all the revolutionary events, the abdication of the tsar Nicholas II and Russia's participation in the First World War.
\end{abstract}

Keywords: Russian revolution, cartoons, newspapers, Madrid.

\title{
Introducción y metodología
}

La Revolución rusa fue unos de los acontecimientos más importantes del siglo XX, no solo por lo que supuso para Rusia (el fin de la dinastía Romanov, la toma del poder por el proletariado saltándose el paso previo de la revolución burguesa o la implantación del primer estado comunista), sino también porque la revolución, el comunismo y la lucha de clases inspiraron movimientos similares en otros países -como la revolución alemana, la revolución húngara o el trienio bolchevique en España, entre otros-, y provocaron la reacción de grupos y países que no simpatizaron con el sistema soviético con la consiguiente división del mundo en dos bloques: el comunista y el capitalista.

Como acontecimiento de tanta relevancia ha sido estudiado desde múltiples perspectivas incluyendo trabajos sobre las noticias que se publicaron en diferentes países (Lippmann y Merz, 1920; Kriesberg, 1946; Oliveira, 1973; Donnini, 1976; O’Reilly, 1979; Andrade, 2017). En España la investigación sobre este asunto se ha centrado principalmente en los periódicos madrileños $-A B C$, El Socialista, El Sol, El Debate, El País - La Correspondencia de España-, pero también en publicaciones de otras ciudades como el barcelonés Solidaridad Obrera o los murcianos El Liberal y El Tiempo (Lazo Díaz, 1975; Almuiña Fernández; 1997; Egea Bruno, 2017; Maestro, 2017). Estos trabajos han demostrado que en España la cobertura informativa de la Revolución rusa estuvo marcada por la influencia de la Primera Guerra Mundial en la explicación de los sucesos. 
Un aspecto de los periódicos españoles ha pasado casi desapercibido por la investigación: las viñetas. Solamente se han encontrado los trabajos de Laguna Platero y Martínez (2017) y de Garcia Sala (2012) al respecto. Laguna Platero y Martínez, con un profundo conocimiento del momento histórico, analizaron fundamentalmente las viñetas de la revolución de octubre, mientras que Garcia Sala, aunque sin centrarse en la revolución, ofreció datos sobre la imagen del oso ruso en la prensa española durante un largo periodo, incluyendo 1917.

En el ámbito internacional se han encontrado más trabajos sobre las viñetas de Rusia en la prensa, pero principalmente enmarcados dentro del contexto de la Gran Guerra como fue el caso de Pytlovana (2016) analizando las viñetas del semanario satírico inglés Punch, o el de Douglas (1995) donde en su libro sobre las viñetas de la Primera Guerra Mundial dedicó tres capítulos a la Revolución rusa. Destacan, además, el trabajo de De Lazari, Riabov y Zakowska (2019) que analizaron la metáfora del oso empleada por periódicos de Rusia, Alemania, Gran Bretaña y Polonia para explicar diferentes acontecimientos revolucionarios rusos, o los estudios sobre la imagen de la revolución en las ilustraciones publicadas por la propia prensa rusa (Milne, 2006; IgnatenkoDesanlis, 2015 y 2016; Aleksandrovna Filippova, 2017; Etty, 2017).

La investigación que ahora se propone pretende profundizar en el análisis de la cobertura informativa de la Revolución rusa en España al centrarse en un aspecto específico: las viñetas que dibujantes españoles hicieron sobre los acontecimientos revolucionarios del país moscovita en 1917. Se trata de comprender qué imagen transmitieron las viñetas de la Revolución rusa y en qué aspectos de la misma se centraron más.

Para ello se han analizado las ilustraciones ${ }^{2}$ sobre la Revolución rusa aparecidas a lo largo de 1917 en los siguientes periódicos madrileños: El Imparcial, El Sol, España y Heraldo de Madrid, enmarcados dentro de una corriente ideológica liberal y aliadófila; Blanco y Negro, El Mentidero, La Acción y La Nación, ubicados en una ideología conservadora y germanófila; y El Día, de carácter liberal-moderado y germanófilo. ${ }^{3}$ La investigación se centra en los impresos de la capital porque fueron los que disponían de mejores tecnologías, mayor variedad de dibujantes, más cantidad de páginas, tiradas elevadas, y un alcance mayor ya que los periódicos se vendían también en otras provincias (Gómez Aparicio, 1974; Cruz Seoane y Sáiz, 1998; Fuentes y Fernández Sebastián, 1998).

2 En el trabajo se emplean los términos viñeta e ilustración como sinónimos.

3 No solo es interesante conocer qué ideologías mantuvieron los periódicos, sino también qué posición con respecto a la guerra defendieron ya que, aunque España no participó en ella, sí que hubo en la sociedad, en los políticos o en los periódicos una polarización a favor de uno u otro bando y Rusia estaba inmersa en la contienda junto a los aliados (Fuentes Codera, 2014). 
De cada uno de estos periódicos se ha realizado un análisis de todos los ejemplares impresos desde marzo de 1917 (mes en el que en España ocurre la revolución de febrero) hasta diciembre de $1917^{4}$ para seleccionar del conjunto de viñetas publicadas las que hicieran referencia a la Revolución rusa. La muestra quedó conformada por un total de 84 ilustraciones.

Para analizarlas se ha empleado la metodología del análisis de contenido con técnicas tanto cuantitativas como cualitativas, destacando estas últimas ya que en el análisis cualitativo se tienen en cuenta las características, los matices o los significados profundos del contenido, así como su relación con el contexto, aspectos que no se consideran cuando se realiza un análisis cuantitativo. Es decir, no solo se quiere saber qué aspectos eran los más tratados, sino también los significados y las relaciones entre ellos (Altheide, 1996; López-Aranguren, 1996; Andréu Abela, 2001; Krippensdorff, 2014).

Una vez definido el objeto de la investigación y seleccionados los datos para el análisis (de los que no se ha escogido ningún muestreo lo que permite el criterio de representatividad) se ha realizado, siguiendo la metodología del análisis de contenido, un registro y codificación de los datos clasificándolos en categorías. Dado que «el éxito o fracaso de la aplicación de esta técnica de análisis depende fundamentalmente del sistema de categorías empleado» (López-Aranguren, 1996: 476), se ha efectuado una primera definición de categorías provisional (método de tanteo) siguiendo como ejemplo las proporcionadas por Meléndez Malavé (2005: 43-49) y Suárez Romero (2015: 240-241). Tras ser aplicado a una pequeña muestra de las viñetas, las categorías fueron ajustadas y quedaron definidas como se establece en la ficha de análisis de la tabla 1.

Además, se han tenido en cuenta dos cuestiones más. En primer lugar, el contexto de los datos. No se pueden entender las viñetas desconociendo qué pasaba a nivel internacional, nacional e incluso local. En segundo lugar, se ha recurrido en ocasiones a unidades de contexto (artículos publicados en las páginas de los periódicos) para entender adecuadamente el significado de las viñetas (López-Aranguren, 1996).

4 Los archivos digitalizados se encuentran disponibles en la hemeroteca digital de la Biblioteca Nacional de España (http://www.bne.es/es/Catalogos/HemerotecaDigital/) y en la hemeroteca de $A B C$ (https://www.abc.es/archivo/periodicos/) [Fecha de consulta de ambas: 18-03-2020]. 


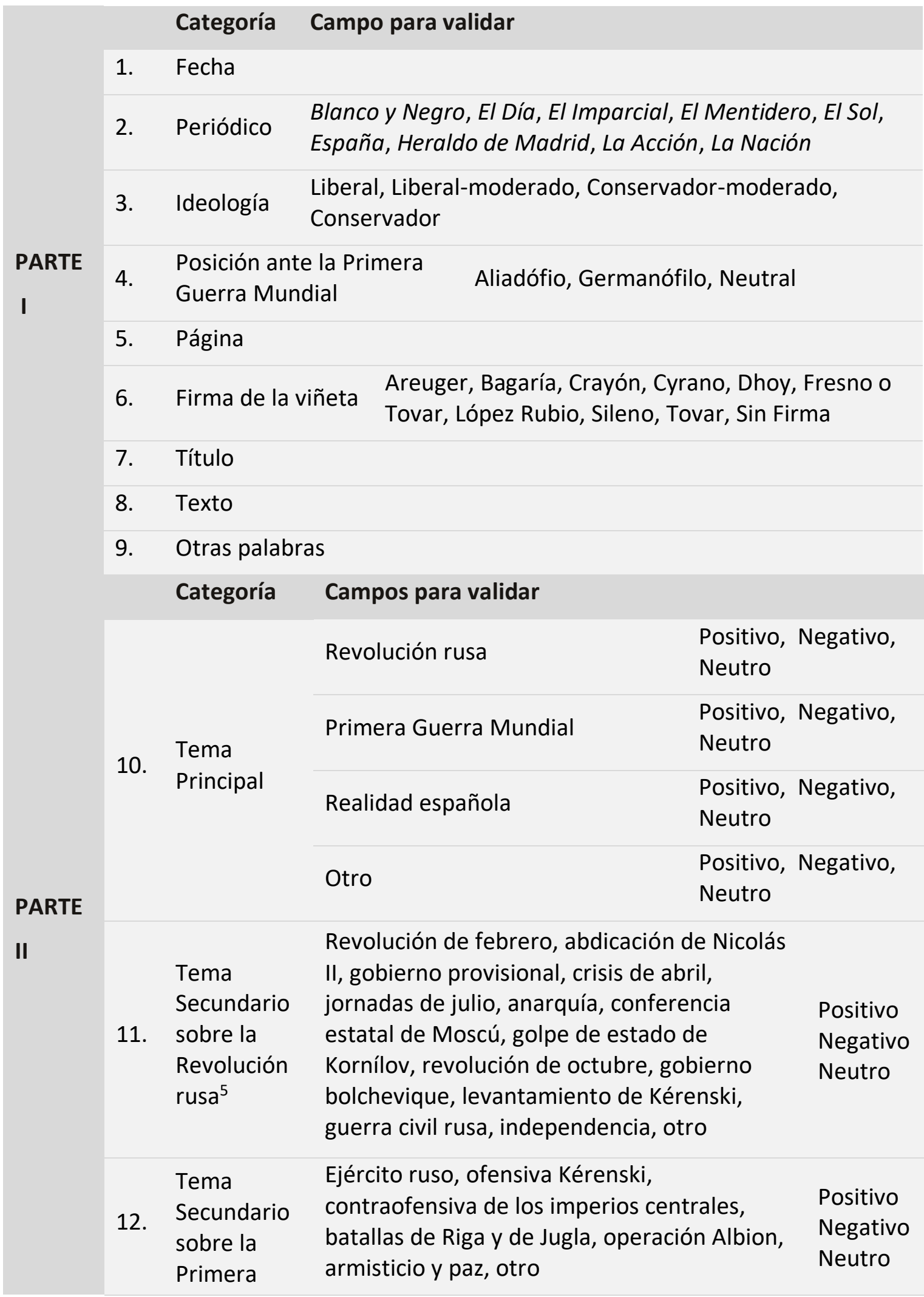

5 Los temas secundarios son independientes del tema principal. Por ejemplo, si una viñeta tiene de tema principal "Revolución rusa", puede también tener como tema secundario "Gobierno de Romanones". 


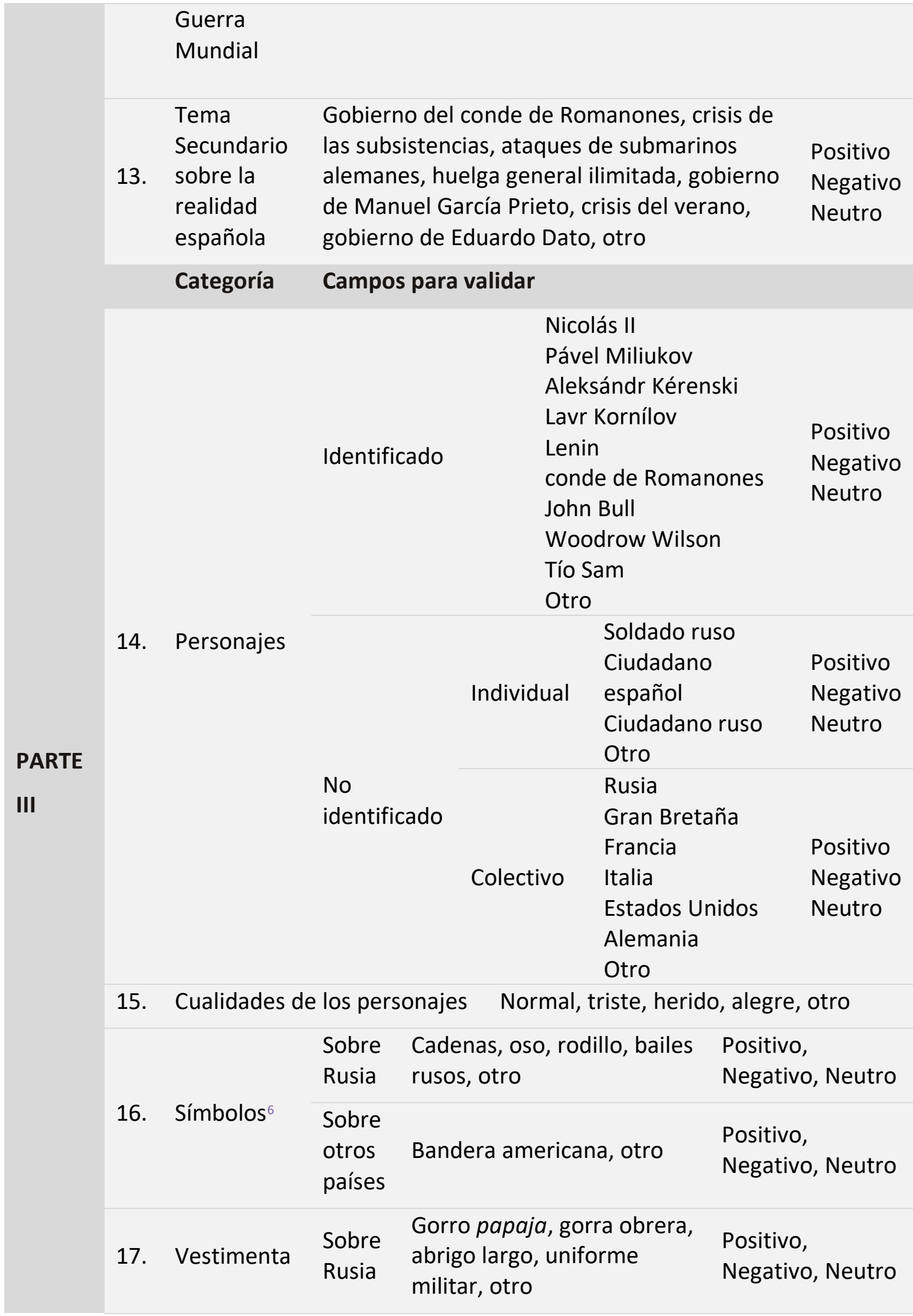

6 De los símbolos y las vestimentas se pueden seleccionar varios aspectos al mismo tiempo. 


$\begin{array}{lll} & \text { Casco prusiano, sombrero } & \\ \text { Sobre } & \text { del regimiento Bersaglieri, } & \text { Positivo, } \\ \text { otros } & \text { sombrero de copa alta, } & \text { Negativo, Neutro } \\ \text { países } & \begin{array}{l}\text { traje militar inglés, casco } \\ \\ \end{array} & \\ & \text { Adrian, quepis, otro } & \end{array}$

18. Cualidades de

Normal, rota, de lujo, elegante, sucia, otro

19. Escenario

Sin escenario, sobre la revolución, sobre guerra, España, otro

20. Cualidades del escenario

Normal, desolado, destrozado, como un paraíso, otro

21. Otras anotaciones

Fuente: Elaboración propia.

Cada una de las 84 viñetas que componen los datos de la investigación se ha estudiado siguiendo la ficha de análisis. Con ello se comprueba que las viñetas sobre la Revolución rusa fueron más numerosas en los periódicos de ideologías conservadoras $(67,86 \%)$ que en los liberales (32,14\%), y en los germanófilos (78,57\%) que en los aliadófilos (21,43\%). Además, aunque fue una temática constante a lo largo de todo 1917, fueron los meses de marzo (mes de la primera revolución) y diciembre (inicio de las negociaciones de paz) cuando se publicaron la mayor cantidad de viñetas: el $30,95 \%$ y el $16,67 \%$ del total respectivamente. De las 84 viñetas encontradas, no todas estuvieron firmadas. Las que sí lo estaban fueron de: Areuger, ${ }^{7}$ Bagaría, Crayón, Cyrano, Dhoy, Fresno o Tovar, López Rubio, Sileno y Tovar. Si de los periódicos se había incidido en las ideologías de los mismos, menos importancia cobran las preferencias políticas de los dibujantes. De hecho, algunos de ellos publicaron sus ilustraciones en periódicos de diferentes ideologías. Por ejemplo, Dhoy firmó viñetas para La Nación y Heraldo de Madrid; Sileno en Heraldo de Madrid y Blanco y Negro; y Tovar dibujó tanto para El Imparcial, El Día y Heraldo de Madrid, como para Blanco y Negro.

El estudio de las viñetas de los periódicos cobra especial importancia: son un género de opinión y, por tanto, contribuye a la creación de opinión en la sociedad (Tejeiro Salguero y León Gross, 2009); destacan por sus vínculos con la actualidad y su popularidad (Segado Boj, 2009b); y porque en una época de elevado analfabetismo (Vilanova Ribas y Moreno Juliá, 1992) el componente visual de los periódicos cobraba importancia no solo como herramienta de opinión o entretenimiento, sino, sobre todo, como elemento

7 Hay cuatro ilustraciones que, yendo sin firmas, se han atribuido a Areuger por presentar un estilo similar a sus demás viñetas y por publicarse en La Acción, periódico del que él fue el principal ilustrador. Son las correspondientes a los días: 16, 17, 18 y 19 de marzo de 1917. 
para atraer la atención del espectador, conseguir más ventas de ejemplares y acercar el periódico y la realidad a más personas.

Las ilustraciones en los periódicos españoles han sido muy estudiadas. Hay trabajos tanto de épocas pasadas, sobre todo en lo relativo a la segunda república, la dictadura franquista y la transición (Tubau, 1987; Fuentes Aragonés, 1991; Martínez de las Heras, 1991; Saiz, 1991; Meléndez Malavé, 2007; Segado Boj, 2009a; Segado Boj, 2009b; Martín Sánchez, 2010; Martín, 2011; Segado Boj, 2012; Campos Pérez, 2013; Castañeda Zumeta y Pineda-Martínez, 2016), como de la época actual centrados, por ejemplo, en la imagen de la casa real, la representación de la mujer o las políticas de austeridad durante la crisis económica (Domínguez y Mateu, 2014; Hernández Herrera, 2019; Fernández Toledo y Villaplana-Ruiz, 2019). También hay trabajos que han analizado aspectos internacionales en el humor gráfico español como la presencia de los líderes extranjeros o la guerra fría (Suárez Romero, 2015; Morera Hernández, 2018).

\section{Una historia contada con símbolos}

Los textos que acompañaban a las viñetas eran breves, por lo que los ilustradores las completaron con símbolos que permitían al lector identificar qué era lo que el autor contaba. Fueron símbolos, muchas veces estereotipados, que se repetían, incluso entre los diferentes autores, dando la idea, por un lado, de que el espectador los conocía, que formaba parte de su bagaje cultural y, por otro lado, que el símbolo se mantendría en la memoria colectiva al subrayarlo de nuevo y difundirlo. En las ilustraciones analizadas han sido dos los tipos de símbolos que se han encontrado: sobre personas y sobre realidades que solo pueden entenderse según el contexto social, político y cultural del momento (El Refaie, 2003).

En lo relativo a las personas algunas características en su vestimenta dieron la pista de sobre quién se trataba. Pero más que sobre personas concretas sobre países. Los alemanes fueron identificados por el casco prusiano con el pincho en la parte superior. Los italianos por el sombrero tradicional del regimiento Bersaglieri de ala ancha y decorado con plumas. Estados Unidos por el sombrero de copa alta y la bandera americana. Sus representaciones hacían referencia, habitualmente, o a Woodrow Wilson o al Tío Sam. En este último caso el dibujo llevaba perilla. Reino Unido apareció representado o bien con John Bull -hombre que tradicionalmente representa a Inglaterra- o con un hombre alto y delgado, con un traje militar inglés, monóculo, pipa y un pequeño sombrero en la alargada y, a veces, calva cabeza. El personaje de Rusia llevaba o el gorro papaja o una gorra con visera típica de las clases proletarias, un abrigo largo y, normalmente, solía ser un hombre corpulento. Y Francia era representada por un hombre, a menudo bajo, con el casco Adrian (y su cresta en la parte superior) o un 
quepis, como si fuera un poilus, con abrigo que se abría en la zona de las piernas y unos pantalones abombados. Además, aunque a veces las ilustraciones estaban llenas de personajes rusos, la mayoría no hacían referencia a alguien en concreto. Solamente se han encontrado dos personajes identificados claramente: Nicolás II, dibujado con un gran bigote, el pelo o con grandes entradas o con la raya al lado y, en ocasiones, con la corona imperial; y Aleksándr Kérenski que apareció en una única viñeta delgado, de rostro alargado y una nariz grande.

De la misma manera, la realidad rusa de 1917 tuvo en las viñetas unos elementos identificativos usados como metáforas como fueron el oso, las cadenas, el rodillo, o los bailes rusos.

La representación zoomórfica de Rusia como un oso se ha usado a menudo en la sociedad occidental para identificar al país y a su pueblo. En las ilustraciones apareció o bien famélico y triste, ejemplo de la difícil situación en la que se hallaba el país como consecuencia, sobre todo, de la guerra y la autocracia, o bien fuerte y con capacidad para seguir peleando. Garcia Sala (2012: 142) concluyó que la prensa española atribuía al oso ruso características como la fuerza, la agresión, el peligro, la barbarie o el despotismo, similar a la imagen transmitida por la prensa europea antes de la revolución (recogido en Pytlovana, 2016: 144-145).

Las cadenas representaban la esclavitud. Pero en todas las ilustraciones aparecieron rotas como muestra de la libertad que Rusia había conseguido con la revolución tras la monarquía de Nicolás II. El rodillo, rulo o apisonadora era la ejemplificación del ejército ruso. Un mito más que una realidad construido en la idea de la capacidad rusa para movilizar a grandes cantidades de hombres. En la prensa se dio la imagen de que el ejército ruso era como una apisonadora: tan poderoso que aplastaría todo aquello que se encontrase a su paso. $Y$ en las viñetas lo utilizaron de forma literal, con la utilización de un cilindro.

Por último, con respecto a los bailes rusos, la compañía de ballets rusos de Serguéi Diáguilev inició en 1916 una exitosa gira por los teatros españoles incluyendo el Teatro Real de Madrid donde repitieron temporada en 1917. Los ilustradores madrileños, que tradujeron la palabra ballet como baile, aprovecharon en sus viñetas sobre Rusia la fama adquirida por el espectáculo para reflejar diferentes acontecimientos que ocurrieron en Rusia a lo largo de 1917. 


\section{La revolución, el zar y la realidad española}

Una de las primeras cuestiones que recogieron los ilustradores sobre la Revolución rusa fue la abdicación del zar Nicolás II. Al analizar la imagen del zar ofrecida por las viñetas hay que hacer referencia a la aliadofilia y germanofilia de los periódicos madrileños dado que Nicolás II era el emperador de un país que estaba participando en la Guerra Mundial junto a los aliados.

La Nación (ilustración 1) publicó una viñeta sin firma en la que un mazo, que llevaba escrito Rodzianko, ${ }^{8}$ golpeaba la corona imperial que ya se estaba cayendo de la cabeza de un triste Nicolás II mientras en el fondo una ciudad rusa bullía en revolución. La viñeta publicada en un periódico de tendencia germanófila no dudó en criticar a Inglaterra por su inacción ante el derrocamiento: "iSea usted primo de Jorge V para esto!» (Sin firma, La Nación, 18-03-1917: 1). De hecho, los países que se consideraban aliados de Rusia no hicieron nada para evitar la caída de un monarca que, aunque autoritario, les había ayudado en la guerra pues las acciones del ejército ruso en el frente oriental, es verdad que algunas con poco éxito, permitieron rebajar la tensión del frente occidental ante los ataques alemanes.

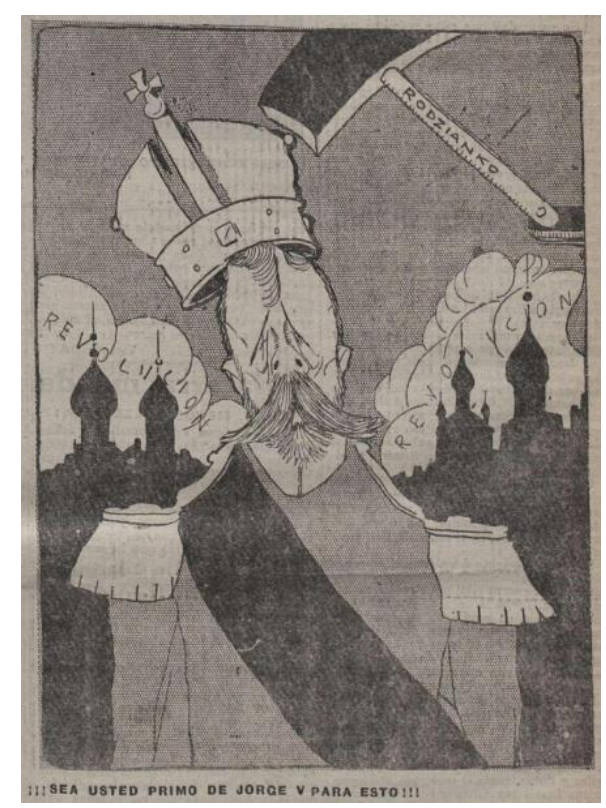

Ilustración 1. Sin firma, La Nación, 18-03-1917: 1.

8 Mijaíl Rodzianko, que se presentó ante el zarévich Alexéi como el hombre más gordo de Rusia (Trotski, 2008: 164), fue presidente de la Duma Imperial y presidente del Comité Provisional de la Duma que se constituyó tras la revolución de febrero. Informó a Nicolás II de los graves acontecimientos de Petrogrado y fue uno de los políticos que entablaron las conversaciones que llevaron a la abdicación del zar (Pipes, 2016: 296-347). 
Si la viñeta de La Nación había criticado a los aliados, una viñeta de Heraldo de Madrid publicada el mismo día hizo referencia a los imperios centrales. Para ello destacó cómo el zar, chupete en la boca, estaba bailando "de coronilla» "los bailes rusos» junto al emperador Francisco José I de Austria (Sileno, Heraldo de Madrid, 18-03-1917: 1). Con esta ilustración el periódico, aliadófilo, transmitió una imagen negativa de Nicolás II que se vio reforzada en otras dos viñetas publicadas a los pocos días en las que lo dibujó aplastado por el rodillo ruso, en una muestra de cómo algunos soldados se negaron a obedecer las órdenes de atacar a los manifestantes de Petrogrado y se unieron a ellos (Sileno, Heraldo de Madrid, 24-03-1917: 2), y al preguntarse dónde estaba el zar cuando los rusos luchaban unos contra otros (Sileno, Heraldo de Madrid, 30-03-1917: 2).

Mientras el periódico aliadófilo destacó la responsabilidad del zar en los acontecimientos revolucionarios, los periódicos germanófilos siguieron haciendo referencia a su papel cómo víctima, pero sin olvidar la crítica. Blanco y Negro recogió al "ultimo movilizado» de "la famosa movilización rusa» que no era otro sino un Nicolás II afligido que, maletín de viaje en mano y la corona medio caída, emprendía solo un camino por un campo nevado (Sileno, Blanco y Negro, 25-03-1917: 13). La Nación mostró a un zar que parecía un monstruo con dedos largos y huesudos y que, mientras dejaba caer la corona y el cetro, decía: «Ahí queda eso» (López Rubio, La Nación, 19-031917: 1). Y El Mentidero lo dibujó huyendo del pueblo ruso, como si este lo hubiera tenido esclavizado, atribuyéndole con ironía las siguientes palabras: «Ya era hora de que pudiera gritar iviva la libertad!» (Crayón, El Mentidero, 31-03-1917: 11).

La última imagen que apareció de Nicolás II fue la más representativa de su ya no reinado. En ella no tenía ningún símbolo imperial que destacar: ni corona, ni cetro, ni túnica. Y detrás de él había una nube negra, símbolo, tal vez, de la revolución (López Rubio, La Acción, 03-04-1917: 5).

Además de esta visión deprimente y crítica de Nicolás II, los viñetistas establecieron una conexión entre el zar y el conde de Romanones, líder del partido liberal y presidente del Consejo de Ministro de España en el momento de la Revolución rusa. Fueron dos viñetas, una sin firma en La Acción, pero atribuida a Areuger, y otra de Bagaría en la revista España, que aprovecharon la similitud fonética entre Romanones y Romanov para crear un nuevo personaje, Romanonof o Alvarowich Romanoneff, al que criticaron.

El diario conservador La Acción retrató a Romanones con el uniforme militar ruso y señaló su actitud «patriota» al decir: «¿El pueblo tiene hambre? Pues me pondré al lado del pueblo y meteremos en la cárcel al Gobierno que no cumpla con su deber y ampare las exportaciones» (Areuger, La Acción, 18-03-1917: 1). El término patriota de la ilustración genera confusión al vincularlo con Rusia ya que habría que preguntarse si Nicolás II, zar de un país aliado, era un patriota para un periódico germanófilo. La explicación puede encontrarse en la interpretación que los periódicos pro alemanes dieron de la Revolución rusa: que había sido provocada por la Entente para derrocar al 
gobierno imperial y al zar porque estaban a favor de la paz. Que el zar fuera pacifista significaba que quería acabar con el sufrimiento que la guerra estaba provocando en su pueblo mediante una paz con los imperios centrales -o, con las palabras de la viñeta, ponerse al lado del pueblo ante su hambruna-. Bajo esa idea se entiende la descripción de patriota al zar y la crítica al español "Romanonof" quien no se había puesto del lado del pueblo, ni había castigado a los gobernantes y estaba facilitando, con beneficios económicos para sus empresas, las exportaciones españolas mirando por los intereses de otros países y no por los de su pueblo.

Por otro lado, Bagaría, en la portada del doce de abril de la revista España (ilustración 2), dibujó a Romanones con corona y cetro (el cual estaba haciendo una peineta) sobre un burro. El texto rezaba: «Alvarowich Romanoneff. ¡Revoluciones a mi!... Aprende, Zar Nicolás...» (Bagaría, España, 12-04-1917: 1). La ilustración, fechada siete días antes de la caída de Romanones del gobierno, evidenciaba cómo el presidente estaba gestionando la situación española cosa que no había conseguido el zar en Rusia. Pero debió ser, según la ilustración, de forma negativa debido a la ridiculización.

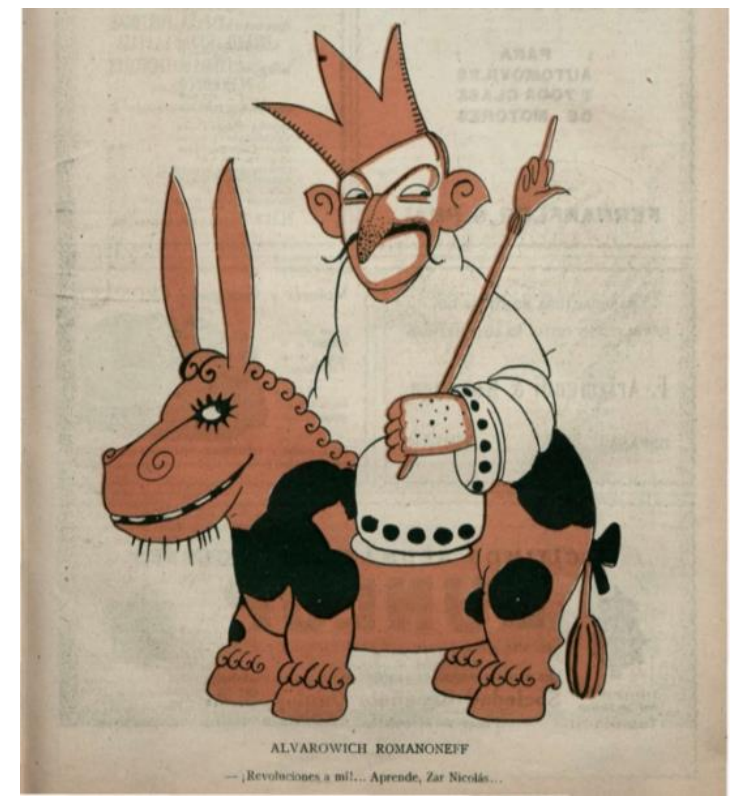

Ilustración 2. Bagaría, España, 12-04-1917: 1.

En el periódico conservador se entiende la crítica al presidente del gobierno español al ser de ideologías contrarias. Pero la portada de la revista liberal España puede generar confusión ya que Romanones pertenecía al partido liberal y era aliadófilo -aunque seguía manteniendo la neutralidad del país-, por lo que podría presuponerse un nivel de afinidad con el periódico que desde 1916 tenía como director a Luis Araquistáin, miembro del PSOE y convencido aliadófilo que utilizó las páginas de la revista para difundir la propaganda aliada, bando que, además, financió la publicación (Montero, 1983). Sin embargo, hay que atender al contexto español para entender la portada de Bagaría. El 29 de marzo de 1917 el gobierno de Romanones suspendió las garantías constitucionales ante el anuncio de huelga general ilimitada realizado por UGT y CNT 
dos días antes. La portada de España del 12 de abril era la primera desde el anuncio de huelga que la revista dedicaba a la situación española ya que las ilustraciones de los dos ejemplares anteriores, del mismo 29 de marzo y del 5 de abril, estaban dedicadas a la contienda mundial. Según los artículos que publicó la revista (Domingo, 1917; Pérez Solís, 1917), el gobierno de Romanones había decidido, ante el anuncio de la huelga y temeroso de una revolución en España, suspender las garantías constitucionales, clausurar centros obreros, realizar detenciones arbitrarias y defenderse mediante sofismas. Es decir, ante un inminente movimiento obrero Romanones había actuado con violencia para detener la revolución, cosa que el zar no había podido hacer. Ahora bien, con esto la revista y Bagaría no estaban alabando las medidas de Romanones, sino criticándolas por desproporcionadas e innecesarias.

Las dos viñetas sobre el zar y Romanones no fueron las únicas conexiones que se hicieron entre España y Rusia. Hubo una gran cantidad de ilustraciones que vincularon ambas realidades, sobre todo en los primeros días de la revolución cuando esta se contó como un movimiento revolucionario de un pueblo hambriento contra unos gobernantes ineficaces para paliar los problemas sociales. Esto fue aprovechado por los periódicos conservadores para publicar viñetas que criticaron, dada la crisis nacional, la realidad española y mostraron el ruso como el camino a seguir. Para entender esto hay que comprender la situación en la que se encontraba España. 1917 fue un año difícil pues los estragos de la Guerra Mundial se notaron también en el país. Como las naciones beligerantes tenían sus industrias centradas en la guerra, tuvieron que importar materias de otros países, caso de la neutral España que en los años de la contienda aumentó el número de sus exportaciones lo que permitió el incremento del PIB y el superávit en la balanza comercial. Sin embargo, las clases populares españolas no se beneficiaron de ello: las condiciones de vida fueron difíciles con carencia de alimentos, inflación y falta de trabajo. A lo que hay que sumar la crisis generada por la guerra submarina alemana (Lacomba Abellán, 1968; Forcadell Álvarez, 1978; Tuñón de Lara, 1985; Aróstegui, Balcells y Elorza, 1986; Nadal, Carreras y Sudrià, 1991; Tuñón de Lara, 1992). Los periódicos conservadores aprovecharon estas condiciones para criticar las políticas del liberal Romanones. Como en Rusia el pueblo hambriento había sido capaz de poner fin a un gobierno que no estaba implementando las medidas adecuadas para acabar con la crisis, los periódicos y dibujantes españoles vieron una oportunidad para, mediante el humor, o bien criticar al presidente del gobierno o bien mostrar la incapacidad del pueblo español para defender unas mejores condiciones de vida.

En marzo, las viñetas de la prensa madrileña conservadora reconocieron la habilidad de los rusos, al contrario que los españoles, para acabar con un gobierno injusto y poner en orden la situación. A pesar de todas las penurias que había en España, los españoles se mantenían inmóviles tomándose las cosas «con la mar de frescura», mientras «los rusos, que han resultado de abrigo, tomaban las cosas con calor» (Areuger, La Acción, 17-031917: 1). La revista satírica El Mentidero también recogió la idea del inmovilismo español 
en dos viñetas. En la primera mostró, tras un revolucionario ruso, a un español -llamado ridículamente "Españita" - sentado tranquilo junto al fuego con una calavera por cabeza y tocando la guitarra diciendo en referencia a Rusia: «Todo eso lo hace el hambre. ¡Yo, gracias a Dios, soy sobrio!». Era una ironía que dijera esas palabras ya que el español, como se apreciaba por la espina de pescado que tenía al fuego, estaba pasando hambre (Sin firma, El Mentidero, 24-03-1917: 1). La segunda referencia ironizó sobre que la población española no fuera capaz de revolucionarse para reclamar mejoras, pero sí gritar por trivialidades como los toros: «Usted verá, si el Camero aprieta más de la cuenta o si el Gallo vuelve la cara, lo que decimos. iMenudo genio tenemos nosotros!», respondía un español cuando un ruso le espetaba que no eran capaces de gritar como habían hecho ellos (Sin firma, El Mentidero, 24-03-1917: 13).

López Rubio también se quejó de la situación española. En una viñeta describió el «hambre», la «miseria», el "parlamentarismo», los "abusos» y el "abandono» que el pueblo español debía soportar bajo el gobierno de Romanones y decía: «iQué bien se estará en Rusia!» (López Rubio, La Nación, 27-03-1917: 1).

De esta forma, los periódicos conservadores se alegraron de la Revolución rusa a pesar de haber supuesto la caída de un monarca que era el último vestigio del autoritarismo que quedaba en Europa. Un autoritarismo que los periódicos conservadores y germanófilos españoles buscaban en Alemania. La ilustración que mejor ejemplificó la alegría por el fin de una etapa fue la que publicó Sileno mostrando cómo en Rusia ya no quedaba nada de valor. En el dibujo aparecía un ruso mirando objetos que había en una especie de mercadillo: el rodillo ruso, el pacto de Londres, un escudo imperial con el águila bicéfala, el Santo Sínodo, el cetro, la corona imperial, un icono religioso y unas pocas armas. Ante ellas, el ruso dijo: "iYo por esto no doy ni medio Kopeck» (Sileno, Blanco y Negro, 20-05-1917: 12). Es decir, todo lo que había sido el pasado de Rusia no valía nada.

Se puede explicar la alegría por el triunfo de la revolución en las ilustraciones de los periódicos conservadores por dos razones. En primer lugar, por la comparación con la situación española, y en segundo lugar (y esto ayuda a comprender por qué los periódicos no mostraron más pena ante la caída del zar ya que España era un país monárquico), porque Rusia, mandada por Nicolás II, que había tomado el mando del ejército, continuaba luchando en la guerra, algo que los periódicos conservadores, que también eran germanófilos convencidos -y algunos financiados (Aubert, 1995: 174175)-, no podían defender. Según las viñetas, era preferible una Rusia sin zar que saliera de la guerra, a una Rusia con Nicolás II apoyando a los aliados.

No hubo viñetas en este sentido en la prensa liberal madrileña. Excepto en España (ilustración 2), y por motivos que ya se han señalado, el resto de los periódicos liberales no mostraron la misma imagen que los conservadores. Lo que sí hicieron fue relacionar la Revolución rusa con la francesa que apareció como el modelo que querían seguir los 
rusos aunque fuera demasiado para ellos. El 30 de marzo Tovar (ilustración 3) dibujó a un famélico ruso vestido con ropa vieja, con la boca abierta y ansioso al ver cómo un camarero le servía «cocina francesa», que no era otra cosa que un pollo que humeaba y goteaba y en el que estaban escritas las palabras libertad y democracia. El ruso dijo: «demasiado fuerte es el plato para mi estómago... ¡Pero, aunque reviente!» (Tovar, EI Imparcial, 30-03-1917: 1). Y el tres de abril Tovar volvió a publicar una viñeta con un ruso regando una planta que parecía muerta (ilustración 4). La regadera llevaba escrita la palabra "revolución» y la planta llevaba puesto el sombrero frigio símbolo de libertad y del republicanismo. El ruso dijo: «Puede ser que cultivando esta planta al estilo francés...» (Tovar, Heraldo de Madrid, 03-04-1917: 1). Es decir, los periódicos liberales consideraron que Rusia seguiría el camino de Francia que era el ejemplo de revolución liberal imperante. Cabe destacar también que en ambas ilustraciones el ruso parece deseoso de iniciar la nueva etapa de libertad. En la primera, además, sus condiciones físicas eran muy débiles, lo que quiere decir que antes de la revolución estaba muy mal. Así, como en los diarios conservadores, los liberales tampoco mostraron mucha pena por la abdicación del zar. Aquí la explicación está en que Rusia era un régimen autocrático. Por eso, tras abril, Nicolás II dejó de aparecer en las viñetas. Ya no interesaba ni a los liberales ni, como se ha destacado, a los conservadores.

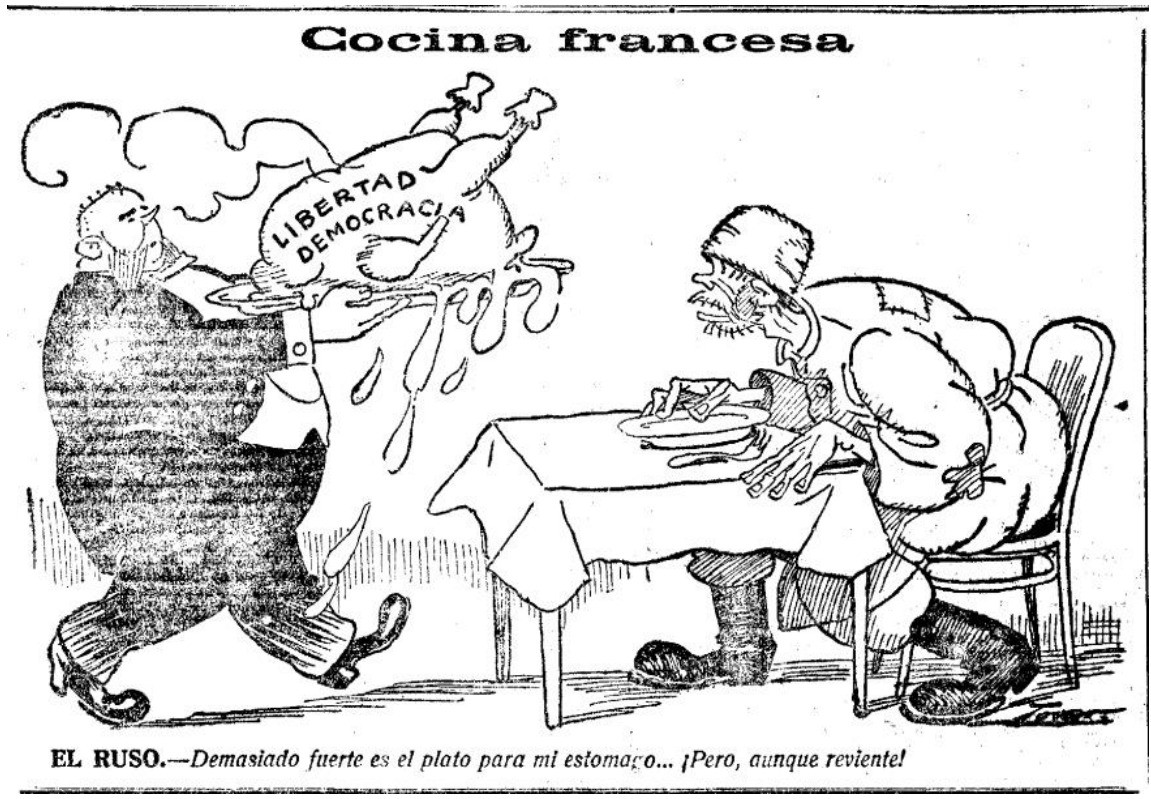

Ilustración 3. Tovar, El Imparcial, 30-03-1917: 1. 


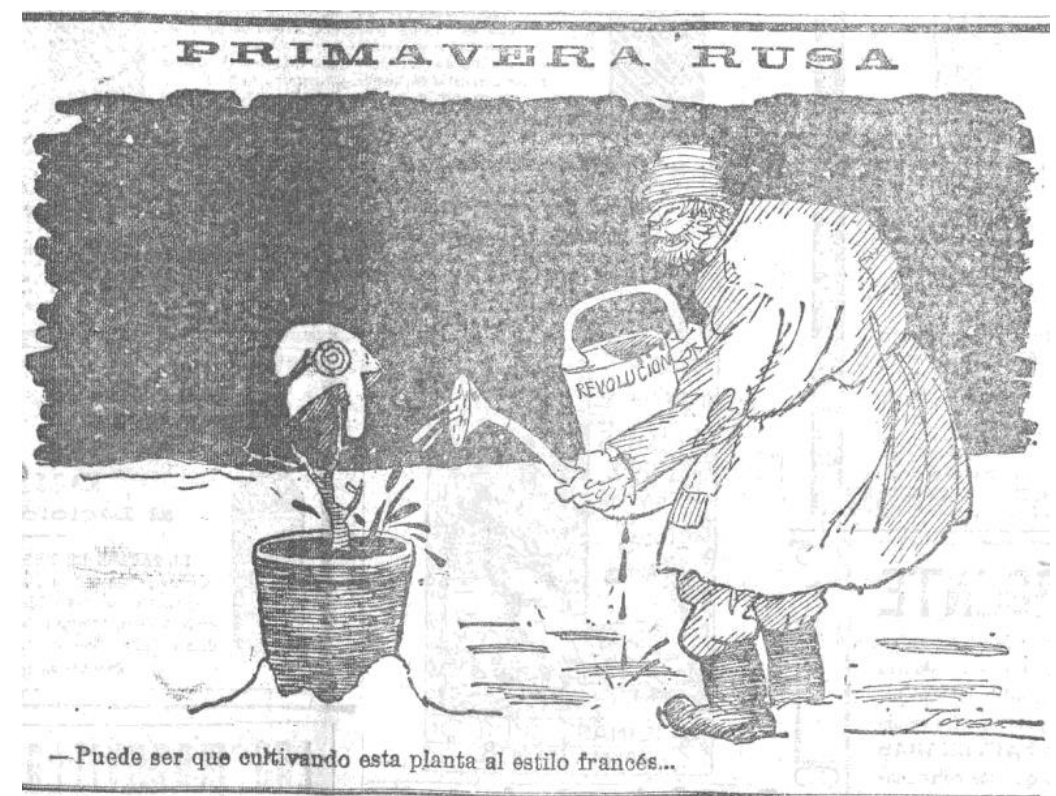

Ilustración 4. Tovar, Heraldo de Madrid, 03-04-1917: 1.

Con el paso de los meses, los periódicos conservadores de Madrid volvieron a conectar España y Rusia en sus viñetas. Así lo hizo Dhoy cuando al hablar dos personas en un bar sobre la declaración de independencia de Siberia y el nombramiento de Nicolás II como su emperador, uno exclamaba: "Chico, yo creo que debían haberle nombrao (sic) a Romanones» (Dhoy, La Nación, 20-11-1917: 5). López Rubio señaló las «ventajas de la revolución». Para ello dibujó a los rusos peleándose durante los acontecimientos de la revolución de octubre, algunos contra Kérenski, otros contra Lenin, y decía: «iLo que son las cosas! Mientras aquí piensan en cerrar las carbonerías, en Rusia se reparte leña gratuitamente» (López Rubio, La Nación, 17-11-1917: 9), haciendo referencia a la escasez que pasaba España. Publicadas en el mes de noviembre, estas viñetas ya no expusieron a Rusia como el camino a seguir, sino que la convirtieron en un elemento con el que criticar, mediante el humor, dos realidades españolas: el partido liberal (que había vuelto al Gobierno tras la presidencia del conservador Eduardo Dato) y la carestía.

Rusia había dejado de ser un paradigma para las viñetas de los periódicos conservadores. La imagen que dieron de Rusia (al margen de los aspectos relacionados con la Primera Guerra Mundial que se verán en el apartado siguiente) fue de caos y ausencia de democracia. El Mentidero publicó una viñeta sobre la continuación en Petrogrado de los bailes rusos «con gran éxito». La imagen no tenía nada que ver con la danza, sino que mostraba a los rusos peleándose entre ellos (Sin firma, El Mentidero, 14-07-1917: 11). Misma idea recogió la revista Blanco y Negro cuando mostró a los rusos bailando entre la corona imperial y una bomba. El texto de Gabaldón explicaba: «En el Real comenzarán muy pronto los bailes rusos que trae Arturo Serrano. En San Petersburgo se están representando ahora con gran espectáculo. Sobre todo, El pájaro de fuego» (Tovar o Fresno, Blanco y Negro, 27-05-1917: 28; Gabaldón, Blanco y Negro, 
27-05-1917: 28). ${ }^{9}$ Otras viñetas de El Mentidero fueron para criticar la misma Revolución rusa: mostrando a un ruso que se cuestionaba para qué le había servido tanta democracia ya que estaba herido (Sin firma, El Mentidero, 04-08-1917: 11), cuando a un ruso se le había «indigestado la democracia» (Sin firma, El Mentidero, 20-10-1917: 11) y destacando que en Rusia «todo el mundo» fuera jefe (Sin firma, El Mentidero, 15-121917: 9).

Los periódicos conservadores se estaban desilusionando con lo que había ocurrido en Rusia. La alegría inicial, que tiene que interpretarse, en parte, por la realidad española, se esfumó pronto al comprobar que la nueva Rusia revolucionaria no saldría de la guerra. Al revés, en julio los moscovitas iniciaron una nueva ofensiva que, aunque resultó ser un fracaso, demostró que los gobernantes rusos estaban empeñados en seguir luchando. Por eso El Mentidero recogió en una viñeta a un ruso malherido tras la lucha en Tarnopol y Stanislau preguntándose para qué le había servido tanta democracia (Sin firma, El Mentidero, 04-08-1917: 11).

Además, una serie de viñetas de López Rubio se centraron no tanto en criticar las medidas adoptadas por los rusos, sino para hacer notar la debilidad en la que quedaban los aliados con ellas. Así, en septiembre dibujaba cómo los aliados veían cada vez más oscuro lo que ocurría en Rusia (López Rubio, El Día, 20-09-1917: 1), y en diciembre, tras la revolución de octubre, publicó dos viñetas, una sobre la publicación de los tratados secretos por parte del gobierno bolchevique en perjuicio de los aliados quienes se quejaban: «iiiPues no me saca las prendas interiores a la vía pública!!!» (López Rubio, El Día, 02-12-1917: 1); y otra sobre que los rusos habían decidido no pagar las deudas contraídas con los aliados (López Rubio, El Mentidero, 22-12-1917: 9).

Por último, hay que destacar que, en general, las viñetas fueron impersonales. De los personajes relevantes de la Revolución rusa solamente aparecieron -aparte de Nicolás II-: Rodzianko, como responsable de la caída del zar (ilustración 1) (Sin firma, La Nación, 18-03-1917: 1); Kérenski, quien ponía música a «los nuevos bailes rusos» (Sileno, Heraldo de Madrid, 02-06-1917: 1) y al observar la derrota de Lavr Kornílov ${ }^{10}$ (López Rubio, El Mentidero, 22-09-1917: 12); Lenin en contra del cual se peleaban algunos rusos, mientras el resto luchaba contra Kérenski (López Rubio, La Nación, 17-11-1917: 9) y a cuyo despacho acudían los aliados en busca de ayuda sin encontrarla (López Rubio, El Día, 05-12-1917: 1); o Kornílov que aparecía como derrotado (López Rubio, El

9 No se sabe quién fue el autor de esta viñeta debido a la confusión que aparece en la página. Al principio dice que los dibujos son de Tovar, pero al final aclara que son de Fresno.

10 Lavr Kornílov, general del ejército ruso, fue comandante del Distrito Militar de Petrogrado al principio de la revolución. A las pocas semanas dimitió y volvió al frente donde fue testigo de la descomposición del ejército. Tras los sucesos de julio Kérenski le ofreció el puesto de comandante en jefe, puesto para el que Kornílov puso condiciones y que supusieron un conflicto entre ambos que se fue acentuando a la vez que la popularidad del general crecía. Patriótico como era, decidió intervenir para salvar a Rusia mediante un intento de golpe de estado que resultó infructuoso (Pipes, 2016: 476-502). 
Mentidero, 22-09-1917: 12). De todos ellos, solamente Kérenski fue dibujado al completo, de Kornílov solo se veía un brazo empuñando una espada al fondo y del resto solo aparecían los nombres escritos.

\section{La participación de Rusia en la Primera Guerra Mundial}

Las ilustraciones de los periódicos aliadófilos mostraron al principio de la revolución la intención de Rusia de seguir luchando con ímpetu junto a los aliados. Así lo hizo Bagaría (ilustración 5) cuando en marzo, con su visión antimilitarista y contra el Káiser, presentó al oso ruso con el propósito de continuar la guerra (Bagaría, España, 22-03-1917: 1). El texto que Luis Araquistáin, director de la revista, escribió sobre la Revolución rusa en el ejemplar da una explicación de la ilustración. Araquistáin relató la evolución de Rusia en los últimos años y cómo, en el contexto de la guerra, Rusia tenía que hacer frente a varios enemigos: la desorganización, la corrupción y la traición. Pero traición no solo «de los vendidos al oro alemán (...) y de los que simpatizaban con Alemania», decía, sino también «de los que contemplaban en una derrota de Rusia o en una paz separada la salvación de la autocracia». Porque, según explicó, la autocracia rusa veía peligrar sus privilegios en beneficio del liberalismo si Rusia salía victoriosa de la guerra. Por ello «no es sorprendente [...] que [...] prefieran una Rusia vencida o desleal a sus compromisos». Y añadía: "Ya es el pueblo ruso dueño de sus destinos como el francés, el inglés y el italiano, y lucha por su democracia, no por ninguna autocracia. iYa está sola Alemania hasta en eso!» (Araquistáin, 1917). Del texto de Araquistáin se entiende la ilustración de Bagaría y las palabras que la acompañaban: "Ya di buena cuenta de los enemigos de casa, ahora vamos con los de fuera». Y en la imagen aparecía un oso fiero, representando al pueblo ruso, paseando sobre calaveras con el casco prusiano dando a entender que la población, al hacer la revolución, había eliminado al enemigo interior, los alemanes o germanófilos que querían sacar a Rusia de la guerra, y ahora se encontraba en disposición de luchar con más contundencia en la contienda mundial junto a los aliados. 


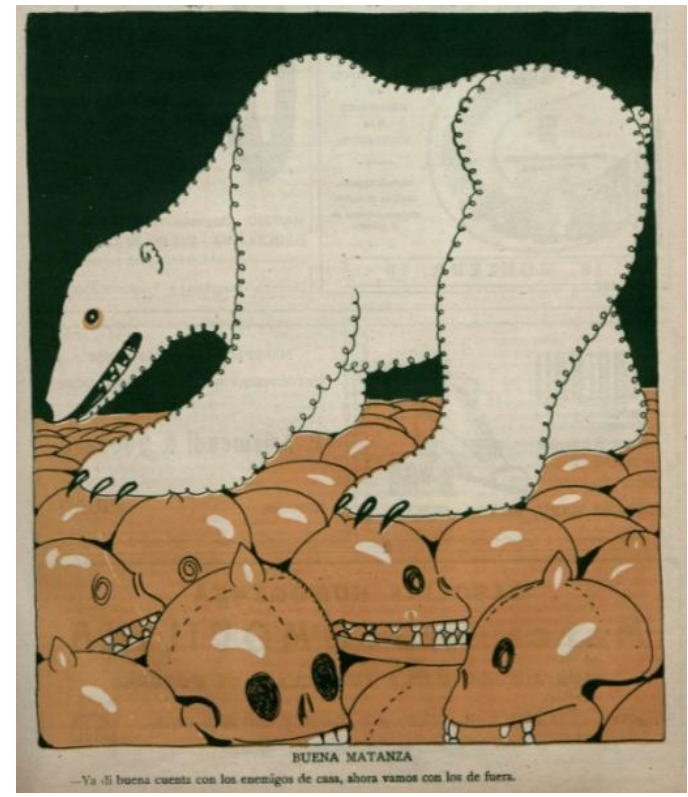

Ilustración 5. Bagaría, España, 22-03-1917: 1.

La ilustración de Tovar en El Imparcial también mostró la idea de que Rusia, tras la revolución, continuaría luchando contra los alemanes. Así, dibujó a unos revolucionarios que pensaban fundir las cadenas de la esclavitud para tener más municiones para la guerra (Tovar, El Imparcial, 25-03-1917: 4). Pero otra ilustración de Tovar no mostró la intención tan clara de Rusia de seguir la guerra ya que dibujó a un oso muy débil por la esclavitud que había soportado ante dos caminos: la guerra o la paz, pero sin decidirse por ninguno (Tovar, El Imparcial, 22-03-1917: 3).

Las ilustraciones en la prensa germanófila y conservadora sirvieron, en un primer momento, para mostrar lo débil que estaba Rusia para seguir luchando junto a la Entente (López Rubio, La Nación, 24-03-1917: 1), criticarla porque centrada en la revolución y en la anarquía no estaba ayudando a sus aliados en la lucha por la victoria (López Rubio, La Nación, 25-04-1917: 1), mostrar cómo Rusia ya no bailaba tan bien las órdenes dadas por Inglaterra -interpretando que los rusos ya no querían seguir en la guerra a sus mandatos- (López Rubio, La Nación, 25-03-1917: 1), o criticar a los mismos aliados porque pretendían que los rusos, débiles como estaban, siguieran luchando junto a ellos. Este fue el caso de la ilustración de Sileno en la que John Bull hablaba con un ruso que estaba muy mal herido (con un brazo en cabestrillo, muletas porque no podía apoyar una pierna y un parche en el ojo) y de fondo una ciudad devastada tras la revolución. John Bull le decía al ruso: «iQué duda tiene! Ahora es cuando está en mejores condiciones para luchar hasta el fin» (Sileno, Blanco y Negro, 01-04-1917: 32).

En un segundo momento, que se inició en el mes de agosto, las viñetas de la revista conservadora y satírica El Mentidero destacaron la huida del ejército ruso ante la proximidad de los alemanes (Sin firma, El Mentidero, 11-08-1917: 10 y Sin firma, El Mentidero, 24-10-1917: 10) y cómo los aliados ya no tenían esperanzas en que el ejército 
ruso les ayudara: «¿No os dará miedo de quedaros solos? Erais muchos. Nosotros nos vamos a ver si así podemos derrotar a los alemanes", les decían unos soldados aliados a los rusos mientras se marchaban del frente (Sin firma, El Mentidero, 29-09-1917: 11). Además, Areuger dibujó el rodillo ruso roto como muestra de la incapacidad del ejército para seguir luchando (Areuger, La Acción, 17-09-1917: 1). Estas viñetas surgieron como consecuencia del fracaso de la ofensiva Kérenski, las deserciones en el ejército ruso y las posteriores ofensivas de los imperios centrales que permitieron a los alemanes acceder al golfo de Riga y que tuvieron como consecuencia la adopción de medidas por parte del gobierno provisional ruso de cara a una posible evacuación de Petrogrado. Areuger reflejó a la idea de que los alemanes estaban acercándose a Petrogrado con una ilustración en la que un soldado alemán llevaba una señal al hombro en la que ponía "San Petersburgo". El texto de la viñeta decía: "Camino de Petrogrado. Pongamos las cosas en su sitio» (ilustración 6). Poner las cosas en su sitio, para el soldado alemán, significaba que Petrogrado volviera a llamarse como antes de la guerra cuando, por ser San Petersburgo una denominación alemana, se decidió su cambio por Petrogrado (Areuger, La Acción, 15-09-1917: 1).

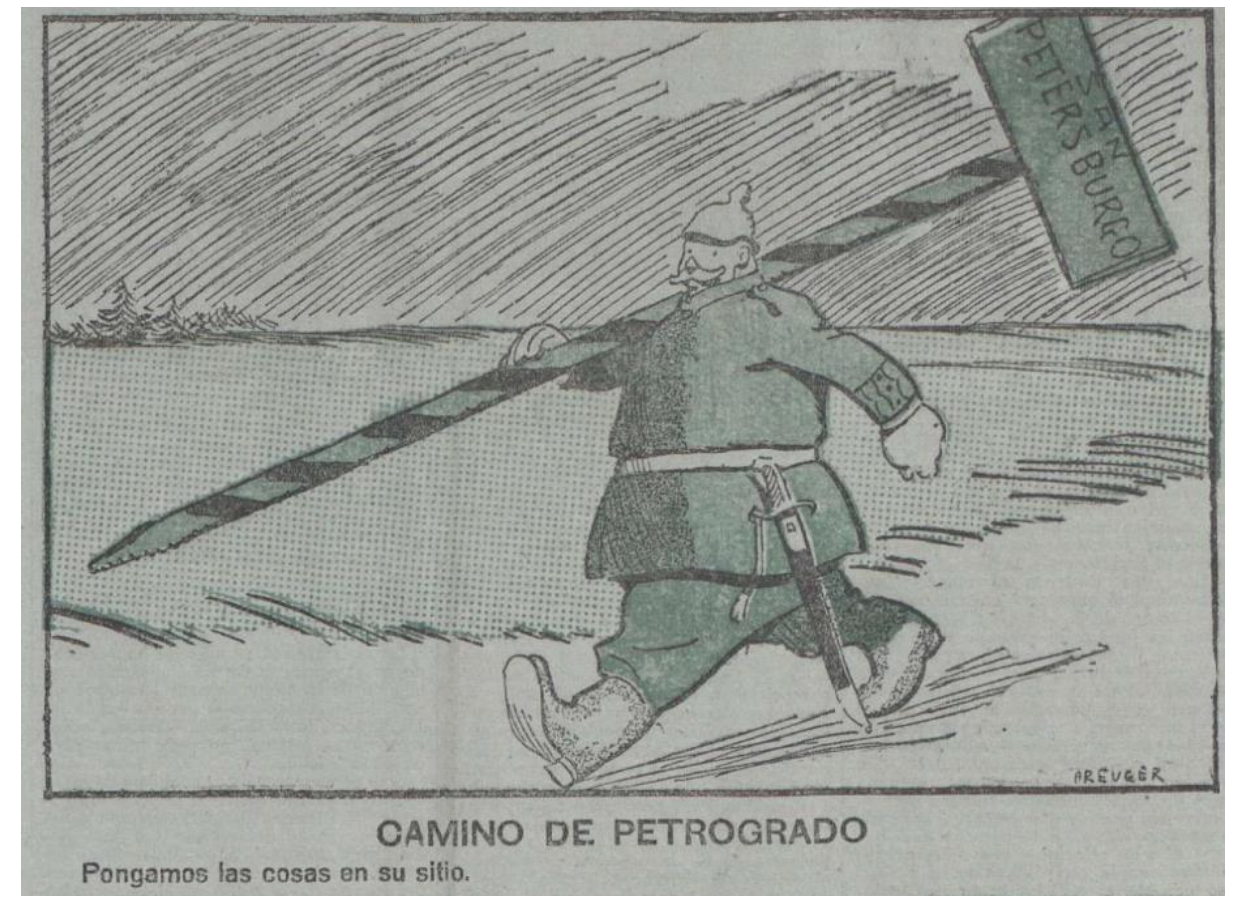

Ilustración 6. Areuger, La Acción, 15-09-1917: 1.

Cuando los bolcheviques se hicieron con el poder en Rusia, el panorama de la guerra cambió ya que estos solicitaron un armisticio a los países beligerantes que los imperios centrales aceptaron dando comienzo a las negociaciones para la paz. Las referencias a la paz en las viñetas se publicaron, tras la segunda revolución, fundamentalmente en los periódicos conservadores. Solamente dos se publicaron en periódicos liberales. Ambas fueron con firma de Bagaría y representaban a Rusia como un oso. En la primera (ilustración 7) Rusia estaba desojando una margarita para ver si hacer o no la paz 
(Bagaría, El Sol, 04-12-1917: 1). La ilustración fue significativa por la censura a la que fue sometida. Cuando Bagaría presentaba sus ilustraciones a la dirección de El Sol las acompañaba con notas sobre posibles modificaciones o diferentes pie permitiendo a los directores que eligiesen el más oportuno. Es lo que ocurrió con la ilustración sobre la Revolución rusa en la que actuó una censura de empresa (permitida por el autor). El texto inicial propuesto era "Honor... deshonor... honor", pero lo acompañó de una nota: «Querido director, si encuentra el pie un poco violento, ponga solo: “Paz Sí... Paz No... Paz Sí... Paz No"» (Elorza, 1988: 177) que fue lo que finalmente se publicó. Aunque habría que preguntarse qué era lo que Bagaría consideraba como honor y deshonor y que la dirección del periódico consideró tan violento como para cambiarlo. La idea de la ilustración de El Sol fue similar a la que transmitió en la segunda viñeta (ilustración 8) donde "la Historia", una especie de contable, estaba pendiente de ubicar la paz rusa con los alemanes bien en el haber o bien en el deber de una cuenta llamada (esta vez no lo habían cambiado) "honor" (Bagaría, España, 06-12-1917: 1).

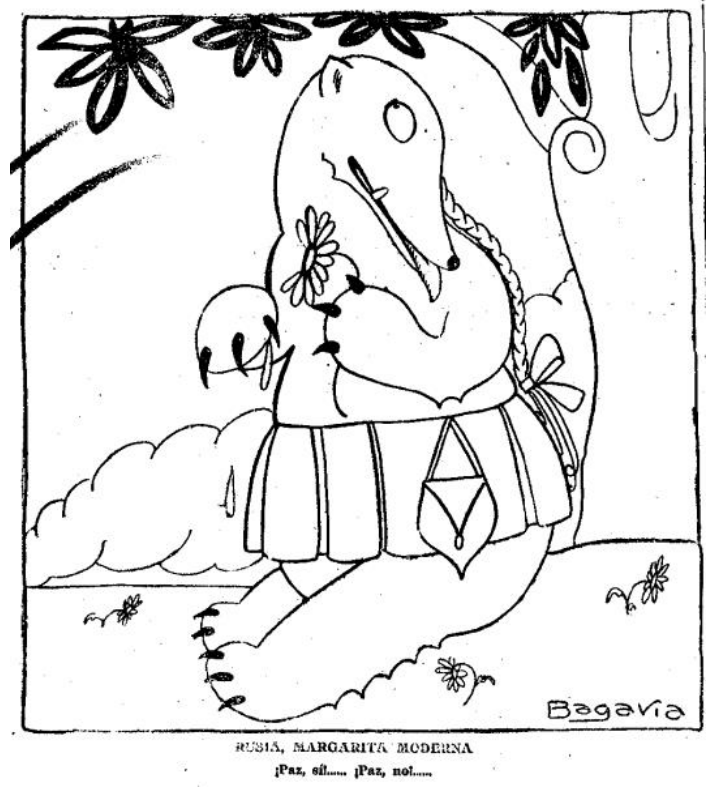

Ilustración 7. Bagaría, El Sol, 04-12-1917: 1.

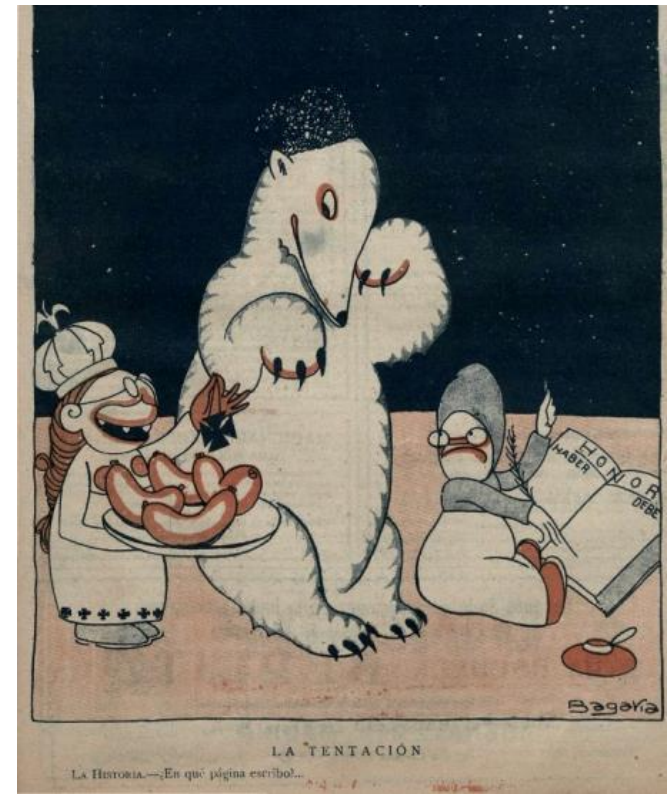

Ilustración 8. Bagaría, España, 06-12-1917: 1.

Las demás ilustraciones se publicaron en periódicos conservadores y germanófilos. López Rubio señaló la «infidelidad» que Rusia estaba cometiendo con los aliados, pero, al mismo tiempo, mostraba al ruso herido mientras Inglaterra y Francia estaban en perfectas condiciones aunque enfadadas (López Rubio, La Nación, 12-11-1917: 11). Igual a la imagen que dio Areuger cuando dibujó cómo un triste oso se ofrecía a un agradable alemán para que le ayudase (Areuger, La Acción, 25-11-1917: 1). La paz, por tanto, se veía como una necesidad para Rusia, para volver a estar en buenas condiciones aunque nadie la escuchara y aunque los demás países aliados no se sumaran a la propuesta y la guerra continuara en el frente occidental, como destacó Tovar en una viñeta en la que se veía a un soldado ruso esquelético sentado en un café gritando: «iA ver! ¿no hay 
quién me sirva?» (Tovar, Blanco y Negro, 18-11-1917: 25). El texto que escribió Gabaldón explicaba:

Si pasáis por el café de la Paz, del que huyó hace tiempo toda la parroquia, encontraréis completamente solo a un moscovita que se hace polvo llamando al camarero.

Pero como no hay ninguno en su turno, su pretensión de que le sirvan café solo y en paz se pierde en el más absoluto vacío (Gabaldón, Blanco y Negro, 18-11-1917: 25).

La paz, según las viñetas, no solo era una necesidad para Rusia, sino que también era interpretada en términos negativos para los aliados y positivos para Alemania. Así, López Rubio dibujó a un prepotente ruso que se despedía de unos incrédulos aliados emprendiendo el camino de la paz que lo llevaba a unos sonrientes soldados de los imperios centrales (López Rubio, El Mentidero, 08-12-1917: 9). La incredulidad y el enfado de los aliados ante la intención de Rusia de firmar el armisticio y conseguir la paz apareció en otras viñetas de López Rubio: al decir que a los aliados ya no les gustaban «los nuevos bailes rusos» que no eran otra cosa que la paz (ilustración 9), cuando intentaron acudir a «Lenine y $C$ a. Sucesores de Kerenski» al apretar el frío, pero estos no los recibieron, o cuando los aliados contemplaron cómo un altivo ruso firmaba el armisticio: "...y lo que él aquí firmó, mantenido está por él», parafraseó el autor las palabras de don Juan Tenorio al relatar sus viles fechorías (por orden: López Rubio, El Día, 29-11-1917: 1; López Rubio, El Día, 05-12-1917: 1; López Rubio, El Día, 20-12-1917: 1). En las tres viñetas los personajes aliados aparecieron disgustados. Por el contrario, mayores beneficios sacaron los alemanes con la paz. La viñeta que mejor representó lo beneficioso que para Alemania sería la paz con Rusia la dibujó López Rubio (ilustración 10) en la que los moscovitas, gracias al armisticio, estaban dejando entrar en su país a los alemanes (López Rubio, La Nación, 21-12-1917: 5). 


\section{LOS NUEVOS BAILES RUSOS}

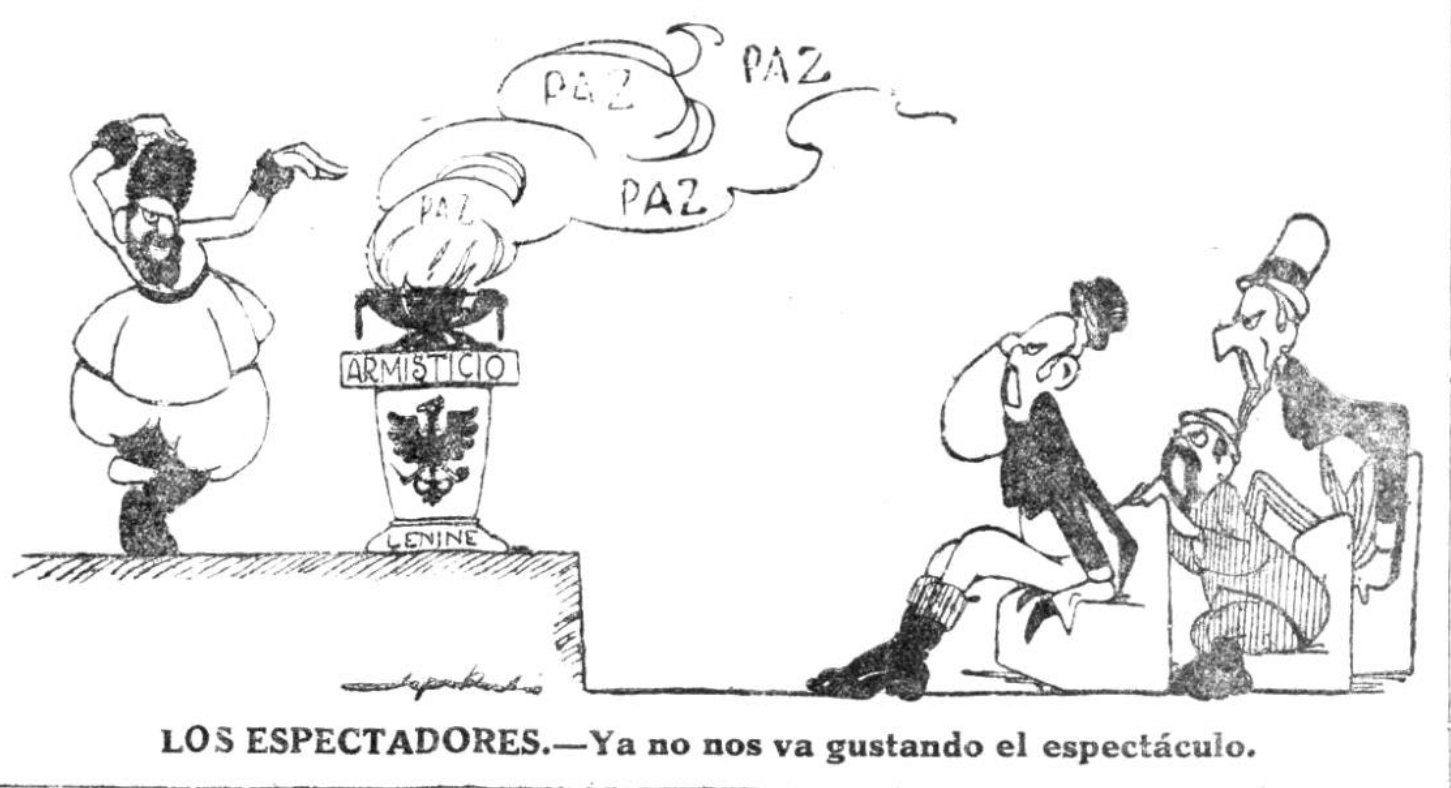

Ilustración 9. López Rubio, El Día, 29-11-1917: 1.

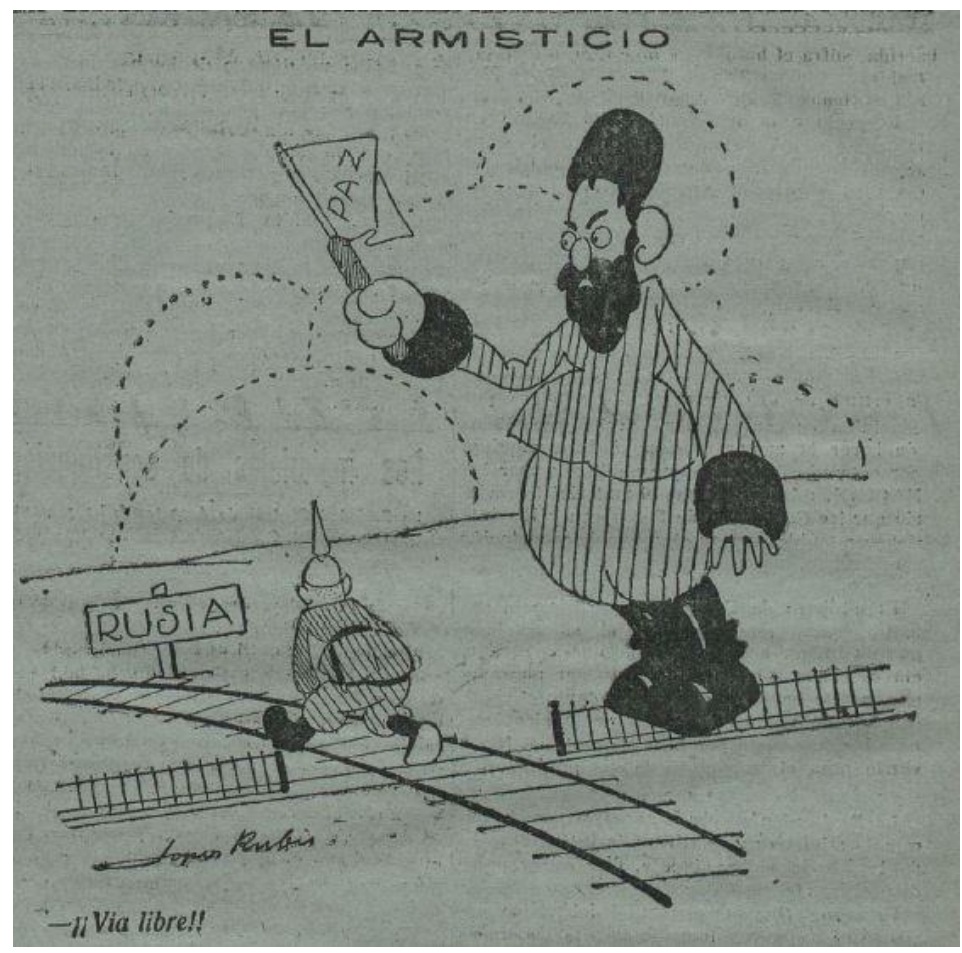

Ilustración 10. López Rubio, La Nación, 21-12-1917: 5. 


\section{Conclusiones}

El análisis de las viñetas sobre la Revolución rusa publicadas por los periódicos de Madrid descubre que el relato se caracterizó por la conexión con la realidad española y la importancia, dentro de todos los acontecimientos que ocurrieron en Rusia en 1917, de la abdicación de Nicolás II y de la participación de Rusia en la Primera Guerra Mundial. Además, los periódicos conservadores y germanófilos fueron los que más viñetas le dedicaron a la realidad rusa en 1917.

El análisis cualitativo de las viñetas ayuda a comprender el significado que las viñetas dieron a esos aspectos y las relaciones que se establecen entre ellos. Para entender el significado es necesario tener en cuenta la ideología de los periódicos y la postura que habían adoptado con respecto a la Primera Guerra Mundial.

En los periódicos germanófilos las viñetas aprovecharon el movimiento revolucionario moscovita para establecer una conexión con la realidad española. La idea liberadora del pueblo ruso frente a una monarquía autoritaria apareció de forma más destacada en los periódicos que se encontraban ideológicamente más cerca del autoritarismo de la monarquía que había sido derrocada. Pero no porque defendieran el fin de la monarquía de Nicolás II, sino porque asemejaron al zar (aliado) con Romanones (aliadófilo) y la realidad rusa con la española donde ambos pueblos estaban pasando penurias por culpa de la guerra. Así, para los periódicos germanófilos el ejemplo ruso no era peligroso, sino el camino a seguir para acabar con gobiernos ineficaces. Sin embargo, esto solo apareció en las primeras semanas. Por el contrario, la conexión entre las realidades rusa y española casi que no apareció en los periódicos liberales. De hecho, estos periódicos, que por su ideología fueron los que más alegría debieron demostrar por el liberalismo y la democracia alcanzada por Rusia, fueron los que menos viñetas publicaron sobre la Revolución rusa.

Con respecto a la abdicación de Nicolás II, Sileno en Heraldo de Madrid acaparó casi todas las viñetas sobre el zar en los periódicos aliadófilos y la imagen que transmitió fue de crítica con Nicolás II señalando su responsabilidad en los sucesos. Mientras que los periódicos germanófilos, con más variedad de diarios y firmas, lo dibujaron como alguien triste y melancólico. Paradójicamente, los periódicos que dieron una imagen más negativa del zar fueron los que tendrían que estar más a su favor por ser el emperador de un país aliado en la Primera Guerra Mundial. La explicación se encuentra en la autocracia de la monarquía rusa y en su acercamiento a Alemania.

En cuanto a la Primera Guerra Mundial, los periódicos aliadófilos mostraron al principio la intención de Rusia de continuar la guerra y al final expusieron el debate que suponía la paz para Rusia. Los periódicos conservadores mostraron más variedad de contenido en referencia a la contienda con dos ideas básicas: el daño que las decisiones rusas en 
la contienda provocaban en los aliados y cómo los imperios centrales, y con ello la paz, eran una solución para los problemas rusos.

Por último señalar que no todo fueron diferencias en la imagen que los periódicos de Madrid dieron de la Revolución rusa ya que hubo una imagen visual unificada. Los ilustradores recurrieron a unos mismos símbolos para reflejar la realidad rusa: los uniformes militares como elemento identificativo, el oso ejemplificando al pueblo moscovita, las cadenas de la esclavitud, los bailes rusos como recurso o el rodillo para hablar del ejército aparecieron en todos los periódicos con independencia de sus ideologías. Otra cosa era el significado que daban a esos símbolos y la intención con la que los usaban.

\section{Referencias bibliográficas}

ALEKSANDROVNA FILIPPOVA, T. (2017): "The Enemy Within and the Enemy Without. Images of the 1917 Revolution in Russian Satirical Journals", en Russian Studies in History, no 56 (1), pp. 51-62.

ALMUIÑA FERNÁNDEZ, C. J. (1997): “La imagen de la Revolución rusa en España (1917)”, en Investigaciones históricas: Época moderna y contemporánea, № 17, pp. 207218.

ALTHEIDE, D. L. (1996): Qualitative Media Analysis, Thousand Oaks, Sage.

ANDRADE, I. S. (2017): "Ecos da revolução russa na imprensa brasileira", en História e Cultura, no 6 (1), pp. 61-82.

ANDRÉU ABELA, J. (2001): "Las técnicas de Análisis de Contenido: Una revisión actualizada", Fundación Centro Estudios Andaluces. Documentos de Trabajo, pp. 1-34. Disponible en Internet (08-05-2020): https://www.centrodeestudiosandaluces.es/publicaciones/tecnicas-de-analisisde-contenido-una-revision-actualizada.

ARAQUISTÁIN, L. (22 de marzo de 1917): “Pan, guerra, libertad", España, pp. 3 y 4.

ARÓSTEGUI, J., BALCELLS, A., ELORZA, A., et al. (1986): La crisis de la Restauración. España entre la Primera Guerra Mundial y la II República. II Coloquio de Segovia sobre Historia Contemporánea de España, dirigido por M. Tuñón de Lara, Madrid, Siglo veintiuno editores.

AUBERT P. (1995): "La propagande étrangère en Espagne dans le premier tiers du XXe siècle”, en Mélanges de la Casa de Velázquez, no 31 (3), pp. 103-176. 
CAMPOS PÉREZ, L. (2013): “El animalario de la Segunda República. Las metáforas zoomórficas en el humor gráfico de la prensa", en HISPANIA NOVA. Revista de Historia Contemporánea, no 11. Disponible en Internet (17-02-2020): http://hispanianova.rediris.es/11/HN2013.pdf.

CASTAÑEDA ZUMETA, A. y PINEDA-MARTÍNEZ, P. (2016): “La reivindicación democrática a través de las viñetas. Las temáticas del humor gráfico en el periódico vasco Egin (1977)", en Revista Latina de Comunicación Social, no 71, pp. 232-248.

CRUZ SEOANE, M. y SÁIZ, M. D. (1998): Historia del Periodismo en España. 3. El siglo XX: 1898-1936, Madrid, Alianza editorial.

DE LAZARI, A., RYABOV, O.V. y ZHAKOVSKA, M. (2019): "The Russian Bear and the Revolution: The Bear Metaphor for Russia in Political Caricatures of 1917-1918", en Vestnik of Saint Petersburg University. Arts, no 9 (2), pp. 325-345.

DOMINGO, M. (4 de diciembre de 1917): "Virtudes de la huelga. Constituirse en peligro", España, p.3.

DOMínGUEZ, M. y MATEU, A. (2014): "Are the winds of change blowing in Spain? Cartoonists' critical analysis of King Juan Carlos' elephant-hunting Trip", en Journalism Studies, no 15 (2), pp. 187-203.

DONNINI, G. (1976): I/ 1917 di Rusiia nella stampa italiana, Milano, Dott. A. Giuffrè Editore.

DOUGLAS, R. (1995): The Great War, 1914-1918: The Cartoonists' Vision, London and New York, Routledge.

EGEA BRUNO, P. M. (2017): "La Revolución rusa en la prensa murciana: de la desinformación a la manipulación”, en Sociología Histórica, no 8, pp. 257-290.

ELORZA, A. (1988): Luis Bagaría. El humor y la política, Barcelona, Anthropos.

EL REFAIE, E. (2003): "Understanding visual metaphor: the example of newspaper cartoons", en Visual Communication, no 2 (1), pp. 75-95.

ETTY, J. (2017): “The Legacy of 1917 in Graphic Satire", en Slavic Review, no 76 (3), pp. 664-674.

FERNÁNDEZ TOLEDO, P. y VILLAPLANA RUIZ, V. (2019): “An analysis of El Roto's newspaper cartoons discourse as social indictment against Spanish austerity policies", en POWER, K., ALI, T. y LEBDUŠKOVÁ, E. (eds.), Discourse Analysis and Austerity Critical Studies from Economics and Linguistics, 1st Edition, New York, Routledge, pp. 311-331. 
FORCADELL ÁLVAREZ, C. (1978): Parlamentarismo y bolchevización: el movimiento obrero español, 1914-1918, Barcelona, Barcelona Crítica.

FUENTES ARAGONÉS, J. F. (1991): "Prensa satírica del Trienio Liberal”, en DOMINGO, J. y MORENO, T. (coords.), Ciento cincuenta años de prensa satírica española: [exposición]. Febrero 1991, Madrid, Concejalía de Cultura del Ayuntamiento de Madrid, pp. 31-36.

FUENTES CODERA, M. (2014): España en la Primera Guerra Mundial. Una movilización cultural, Madrid, Akal.

FUENTES, J. F. y FERNÁNDEZ SEBASTIÁN, J. (1998): Historia del periodismo español, Madrid, Editorial Síntesis.

GABALDÓN, L. (27 de mayo de 1917): “La Semana Cómica”, Blanco y Negro, p. 29.

- (18 de noviembre de 1917): "La Semana Cómica”, Blanco y Negro, p. 25.

GARCIA SALA, I. (2012): “Otgoloski medvéjia retxània: Rossískaia impéria kak beli medved $v$ ispànskoi presse", en RIABOV, O. y DE LAZARI, A. (eds.), "Russki medved»: istória, semiótika, polítika, Moskvà, NLO, pp. 140-149.

GÓMEZ APARICIO, P. (1974): Historia del periodismo español. De las guerras coloniales a la Dictadura, Madrid, Editora Nacional.

HERNÁNDEZ HERRERA, M. (2019): “La representación de la mujer en la viñeta española: construcción y participación femenina", en Estudios sobre el mensaje periodístico, no 25 (2), pp. 869-882.

IGNATENKO-DESANLIS, O. (2015): L'image de la Révolution russe dans la presse satirique russe de 1917, Tesis Doctoral, Université Panthéon-Sorbonne-Paris I.

- (2016) : “L'image de Lénine entre février et octobre 1917", en Revue des études slaves, no 87 (3-4). Disponible en Internet (11-03-2020): http://journals.openedition.org/res/948.

KRIESBERG, M. (1946): "Soviet News in the New York Times", en The Public Opinion Quarterly, no 10 (4), pp. 540-546.

KRIPPENDORFF, K. (2014): Content Analysis. An Introduction to Its Methodology, California, Sage Publication.

LACOMBA ABELLÁN, J. A. (1968): “España en 1917. Ensayo de morfología de una crisis histórica", en Saitabi: revista de la Facultat de Geografia i Història, no 18, pp. 145162. 
LAGUNA PLATERO, A. y MARTíNEZ, F. A. (2017): "Representación de la revolución de octubre en la viñeta española", en Tebeosfera. Tercera Época, no 5. Disponible en Internet

(17-02-2020):

https://www.tebeosfera.com/documentos/representacion de la revolucion de octubre en la vineta espanola.html.

LAZO DÍAZ, A. (1975): La Revolución Rusa en el diario ABC de la época, Sevilla, Secretariado de publicaciones de la Universidad de Sevilla.

LIPPMANN, W. y MERZ, Ch. (Agosto 1920): “A Test of the news”, New Republic.

LÓPEZ-ARANGUREN, E. (1996): “El análisis de contenido”, en GARCÍA FERRANDO, M., IBÁÑEZ, J. y ALVIRA MARTíN, F. R. (coords.), El análisis de la realidad social. Métodos y técnicas de investigación, Madrid, Alianza, pp. 461-492.

MAESTRO, J. (2017): "La Revolución rusa en la prensa española de 1917", en: PAGÈS, P. y GUTIÉRREZ, P. (eds.), La Revolución rusa pasó por aquí, Barcelona, Laertes, pp. 41-62.

MARTÍN, A. (2011): “La historieta española de 1900 a 1951”, en ARBOR, no 187 (2), pp. 63-128.

MARTÍN SÁNCHEZ, I. M. (2010): "La caricatura política durante la II República: El Debate, El Siglo Futuro y Gracia y Justicia", en Brocar, no 34, pp. 203-242.

MARTÍNEZ DE LAS HERAS, A. (1991): "La imagen "antimasónica” en la prensa de la Segunda República", en DOMINGO, J. y MORENO, T. (coords.), Ciento cincuenta años de prensa satírica española: [exposición]. Febrero 1991, Madrid, Concejalía de Cultura del Ayuntamiento de Madrid, pp. 47-58.

MELÉNDEZ MALAVÉ, N. (2005): El humor gráfico en el diario "El País" durante la transición política española (1976-1978), Tesis Doctoral, Universidad de Málaga.

- (2007): "De la lucha de clases a la igualdad de sexos. La sociedad española de la transición a través de las viñetas de Máximo en El País", en CHAPUT, M. C. (coord.), Humor y sociedad en el mundo hispánico contemporáneo, PILAR, Université Paris X-Nanterre, pp. 67-89.

MILNE, L. (2006): “'Novyi Satirikon', 1914-1918: The Patriotic Laughter of the Russian Liberal Intelligentsia during the First World War and the Revolution", en The Slavonic and East European Review, no 84 (4), pp. 639-665.

MONTERO, E. (1983): “Luis Araquistain y la propaganda aliada durante la Primera Guerra Mundial”, en Estudios de historia social, no 24-25, pp. 245-266. 
MORERA HERNÁNDEZ, C. (2018): Humor en tiempos revueltos: el final de la Guerra fría en viñetas: (1979-1989), Valladolid, Ediciones Universidad de Valladolid.

NADAL, J., CARRERAS, A. y SUDRIÀ, C. (coord.) (1991): La economía española en el siglo $X X$. Una perspectiva histórica, Barcelona, editorial Aries.

OLIVEIRA, C. (1973): “A Revolução Russa na imprensa portuguesa da época”, en Análise Social, no 10 (40), pp. 790-811.

O’REILLY, K. (1979): "The Times of London and the Bolshevik Revolution", en Journalism \& Mass Communication Quarterly, no 56 (1), pp. 69-76.

PÉREZ SOLÍS, O. (4 de diciembre de 1917): “La huelga de Valladolid”, España, pp. 4-5.

PIPES, R. (2016): La Revolución rusa, Barcelona, Debate.

PYTLOVANA, L. (2016): "Russia in Punch cartoons: 1914-1918”, еn Військово-науковий вісник, no 25, pp. 138-153.

SAIZ, M. D. (1991): "La prensa satírica en la España del siglo XIX”, en DOMINGO, J. y MORENO, T. (coords.), Ciento cincuenta años de prensa satírica española: [exposición]. Febrero 1991, Madrid, Concejalía de Cultura del Ayuntamiento de Madrid, pp. 37-45.

SEGADO BOJ, F. (2009a): "El camino a las elecciones de 1977: el primer gobierno de Adolfo Suárez en las viñetas de la prensa diaria", en HISPANIA. Revista Española de Historia, vol. LXIX, no. 232, pp. 477-512.

- (2009b): “Un tópico perpetuado. La imagen de la mujer y el feminismo en el humor gráfico de la prensa diaria durante la transición (1974-1977)", en Zer: Revista de estudios de comunicación=Komunikazio ikasketen aldizkaria, no. 27, pp. 203-224.

- (2012): "Vida y muerte del Espíritu del 12 de febrero. El fracaso del último intento reformista del franquismo en el humor gráfico de la prensa diaria (19741975)", en Historia Critica, no 46, pp. 202-224.

SUÁREZ ROMERO, M. (2015): “El humor gráfico como herramienta de crítica: los líderes políticos internacionales en las viñetas de El País", en Revista Científica de Información y Comunicación, no. 12, pp. 227-255.

TEJEIRO SALGUERO, R. y LEÓN GROSS, T. (2009): “Las viñetas de prensa como expresión del periodismo de opinión", en Diálogos de la comunicación, no. 78.

TROTSKI, L. (2008): Historia de la Revolución Rusa, Ediciones digitales Izquierda Revolucionaria. 
TUBAU, I. (1987): El humor gráfico en la prensa del franquismo, Barcelona, Mitre.

TUÑÓN DE LARA, M. (1985): El movimiento obrero en la historia de España (II), Madrid, Sarpe.

- (1992): Poder y sociedad en España, 1900-1931, Barcelona, Espasa Calpe.

VILANOVA RIBAS, M. y MORENO JULIÁ, X. (1992): Atlas de evolución del analfabetismo en España de 1887 a 1981, Madrid, Ministerio de Educación y Ciencia. 